\title{
Coupled Effect of Slope Angle and Terrain Roughness on Tractor Stability
}

\section{QIN, Jiahao}

College of Engineering, China Agricultural University | Beijing Key Laboratory of Optimized Design for Modern Agricultural Equipment | Laboratory of Agricultural Machinery and Production Systems Design, Division of Bioproduction Environmental Sciences, Department of Agroenvironmental Sciences, Faculty of Agriculture, Kyushu University

\section{ZHU, Zhongxiang}

College of Engineering, China Agricultural University | Beijing Key Laboratory of Optimized Design for Modern Agricultural Equipment | Laboratory of Agricultural Machinery and Production Systems Design, Division of Bioproduction Environmental Sciences, Department of Agroenvironmental Sciences, Faculty of Agriculture, Kyushu University

\section{MITSUOKA, Muneshi}

Laboratory of Agricultural Machinery and Production Systems Design, Division of Bioproduction Environmental Sciences, Faculty of Agriculture, Kyushu University

\section{INOUE, Ei j i}

Laboratory of Agricultural Machinery and Production Systems Design, Division of Bioproduction Environmental Sciences, Faculty of Agriculture, Kyushu University

他

https://doi.org/10.5109/1955405

出版情報：九州大学大学院農学研究院紀要. 63 (2)，pp.355-360，2018-09-01. Faculty of Agriculture, Kyushu University バージョン :

権利関係 : 


\title{
Coupled Effect of Slope Angle and Terrain Roughness on Tractor Stability
}

\author{
Jiahao QIN ${ }^{1,2}$, Zhongxiang ZHU ${ }^{1,2 *}$, Muneshi MITSUOKA ${ }^{3}$, Eiji INOUE ${ }^{3}$, Takashi OKAYASU ${ }^{3}$, \\ Yasumaru HIRAI ${ }^{3}$, Zhen $\mathrm{LI}^{1,2}$ and Zhenghe SONG ${ }^{1,2}$
}

Laboratory of Agricultural Machinery and Production Systems Design, Division of Bioproduction Environmental Sciences, Department of Agro-environmental Sciences, Faculty of Agriculture, Kyushu University, Fukuoka 812-8581, Japan

(Received May 1, 2018 and accepted May 8, 2018)

\begin{abstract}
Tractor rollover accidents occur more frequently when tractors operate on uneven, sloping terrain. Previous studies reveal the comprehensive coupled effect of slope angle and terrain roughness on tractor stability by establishing dynamic models. However, the potential mechanism and relation are still unclear and further attention is needed. In this study, we updated a previously developed experimental scalemodel system by including more road roughness classes, and conducting experiments with 56 combinations of the two effects. The results revealed that the rear axle of the tractor is more greatly affected by increased slope angle and road roughness than is the front axle. Weakening either one of these effects can reduce the risk of rollover. Furthermore, a slope angle of $30^{\circ}$ may be the upper limit for stable tractor operation on a slope. Besides, the result shows that for the front axle, the degree of road class makes greater influence on its stability than slope angle while there is an opposite conclusion for the rear axle. The methods and findings of this work could provide engineers a reference for designing tractors with higher stability and provide operators criteria for avoiding rollover.
\end{abstract}

Key words: Tractor rollover, lateral stability, slope angle, terrain roughness

\section{INTRODUCTION}

Wheeled farm tractors are widely used in farming and accidents involving tractor rollover remain an ongoing problem, causing serious injuries or death to operators and damage to tractor. In America, although the number of rollover deaths per farm tractor operator has been reduced by the development of the rollover protection structure (ROPS) over the past 20 years, there were still 3 deaths per 100,000 operators in 2014 (Ayers et al., 2017). In Japan, with terrain dominated by hills and mountains, the situation is more serious, with about 70 operators killed by tractor accidents per year and tractor rollover accounting for $65 \%$ to $80 \%$ of all tractorrelated deaths in recent years, as shown in Figure 1 (Ministry of Agriculture, Forestry and Fisheries of Japan, 2015). Hence, tractor rollovers, which cause huge losses in terms of operator safety and agricultural production, are worthy of further attention.

Tractor rollover has been the subject of previous studies, which can be divided into concern with passive safety protection and active accident prevention. As a typical example of passive safety protection, ROPS was successfully tested in 1956 and John Deere had equipped all new tractors with a ROPS by 1966(Ayers et al., 2017).

College of Engineering, China Agricultural University, Beijing 100083, China

Beijing Key Laboratory of Optimized Design for Modern Agricultural Equipment, China Agricultural University, Beijing 100083, China

${ }^{3}$ Laboratory of Agricultural Machinery and Production Systems Design, Division of Bi-oproduction Environmental Sciences, Department of Agro-environmental Sciences, Faculty of Agriculture, Kyushu University, Japan

* Corresponding author (E-mail: zhuzhonxiang@cau.edu.cn)

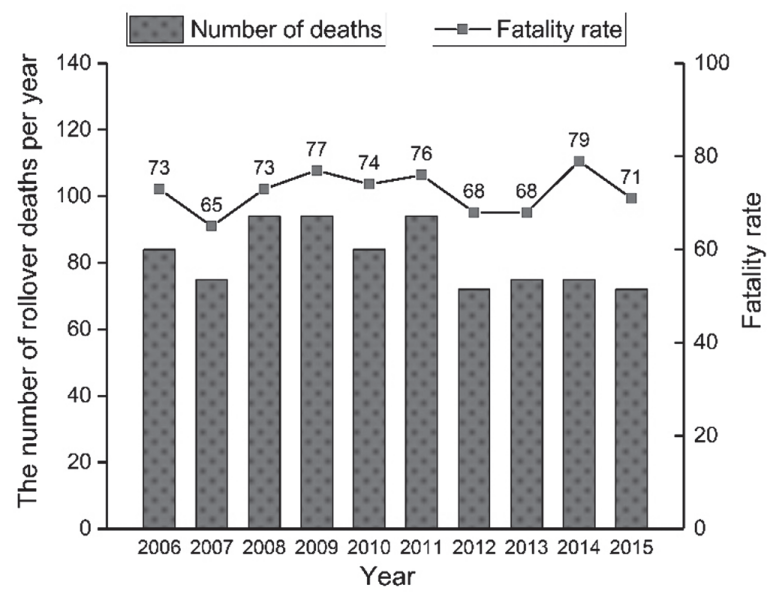

Fig. 1. Annual farm tractor rollover fatalities in Japan from 2006 to 2015 .

As ROPS technology evolved, various enhancements have been developed. For example, an automatically deployable front-mounted ROPS, which can simultaneously increase the height and the upper width of the ROPS using airbag inflators, was designed and tested in 2013 and 2014 (Ballesteros et al., 2013; Ballesteros et al., 2015). On the other hand, previous research has investigated active accident prevention for tractor rollover and established theories revealing the behavior of tractors on slopes (Gibson et al., 1971; Yisa, 1998; Ahmadi, 2011; Vidoni et al., 2015; Bietresato et al., 2015; Li et al., 2014, 2015). These studies have generally concluded that the risk of tractor rollover is a greater when the tractor is operating on slopes or roads with high unevenness. Also, there is a general consensus that the combination of large slope angle and high level of terrain roughness can 
reduce the stability of a tractor. However, no research or experiments have revealed the coupled effect of slope and terrain on tractor stability. Furthermore, the use of real tractors in rollover experiments is limited because such experiments would be dangerous and expensive, so scale models have been employed to study rollover of wheeled farm tractors (Yang, 1991). The advantages of experiments with models include the highlighting of major factors, the ability to ignore secondary factors, and ease of changing parameters, so this approach is becoming much more valued and widely employed (Zhu et al., 1986).

In a previous study, we built a scale-model-based experimental system to investigate parameter sensitivities for tractor stability, and optimized the configuration for improving the lateral stability of the tractors. However, the model was operated only on roads with roughness classes $\mathrm{E}$ and $\mathrm{F}$, a range of road classes too narrow to comprehensively reveal the coupled effect of slope angle and terrain roughness. Thus, the previous experimental system could neither reflect the real world nor provide precise data useful for further research. Moreover, it is known that the uphill wheel has a greater risk to be disturbed than the downhill wheel when a tractor is traveling along the face of a slope. This phenomenon means that rollovers in this situation start with the separation of the uphill wheel and the ground. Because of this, evaluations that focus on the uphill wheel should be more valuable than evaluations of both the uphill and downhill wheels.

In this study, with a focus on comprehensively understanding the coupled effect of slope angle and terrain roughness, we updated the scale-model experimental system by preparing models of all road roughness classes defined by ISO 8608 (2016). Then, we performed traveling tests using 56 different combinations of slope angle and terrain roughness to reveal the potential connections between slope angle and terrain roughness as they relate to tractor stability. Moreover, to interpret the rollover trend, we developed an evaluation index, called the load loss rate $(L L R)$, that characterizes the strength of contact between the ground and uphill wheel. Our approach and conclusions are intended to provide a spe- cific reference for improving tractor stability and reducing the probability of rollover.

\section{MATERIALS AND METHODS}

\section{Scale Models}

A scale-model experimental system was employed to reflect the operation of a tractor more realistically. A needed road roughness update was implemented to cover all possible operating conditions of the tractor.

Specifically, the practical operating conditions of a tractor are varied and irregular, including farm road, farm field, and plowed field. Previous measurements revealed that no single road surface class (ISO 2016) can fully represent these conditions (Matthews, 1966; Torisu, 1979; Ohmiya, 1990), so models of all eight road classes are necessary. Moreover, in previous scale-model studies (Takeda, et al., 2010a; Takeda, et al., 2010b; Taghavifar, 2016), the roads set up for tractor operation always had regular shapes and the obstacles had standardized shapes. However, the surfaces of actual farm roads are irregular and complex, and the road roughness has a high degree of randomness, so a highly regular road surface is not representative. Therefore, in this study, we programed Matlab (R2015a) to generate all eight road classes in the vertical and horizontal directions by employing harmonic superposition. Figure 2(a) shows the surface of class $\mathrm{E}$ as an example of reconstruction of a road class from the profile points in Rhinoceros 5 . Finally, as illustrated in Fig. 2(b), all classes of road roughness were completed by CubeX Duo with all negative vertical values removed. The length and width were set to be $0.1 \mathrm{~m}$ and $0.2 \mathrm{~m}$, respectively, to fit the dimension of the active sensing areas. Specifically, the random surfaces were made into two parts, as it was necessary to provide a run-up stage for the scale-model tractor. In Fig. 2, blue represents the run-up segment, which provided a way for the tractor to adjust itself to a normal driving state, and the gray represents the effective measuring area for which we obtained the experimental data.

In our previous study, the experimental system consisted primarily of a scale-model tractor, a sensing system, and traveling tracks, as shown in Fig. 3. The scale-

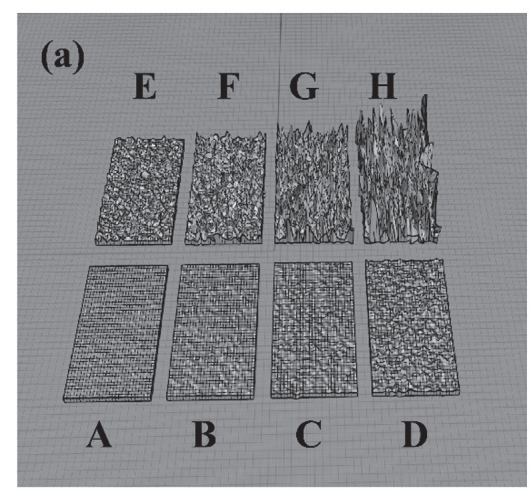

(b)

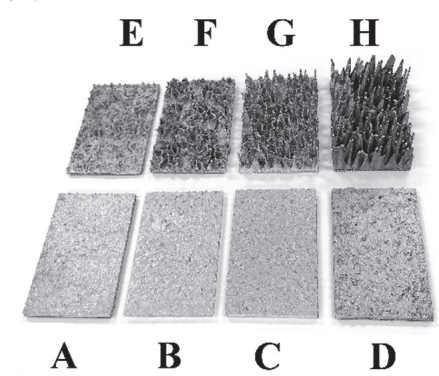

Fig. 2. Generation of scaled random road surfaces for all eight road classes: (a) examples of road surfaces in Rhinoceros 5; (b) samples of the scaled random road surfaces for all eight classes. 


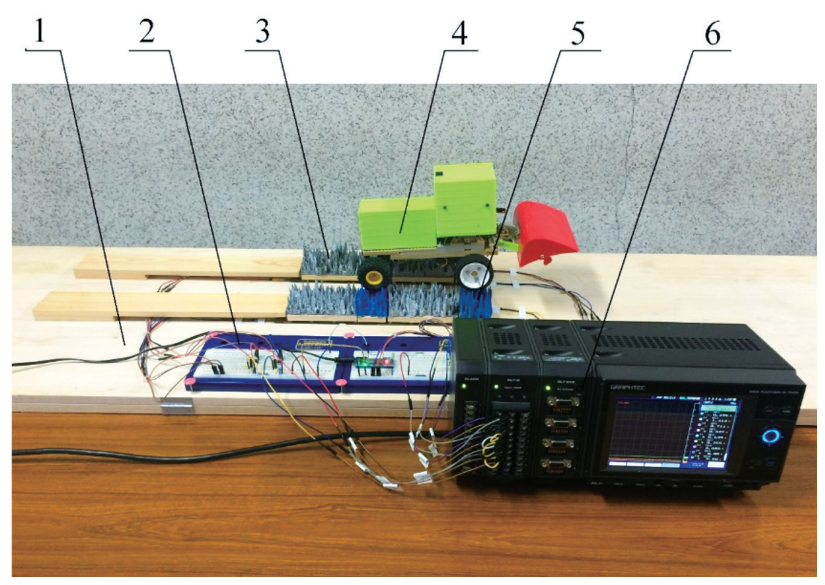

Fig. 3. Experimental setup of the scale-model force measuring system: (1) main baseboard; (2) circuit board; (3) scalemodel road surface; (4) scale-model tractor; (5) scalemodel road for run-up stage; (6) data recorder.

model tractor (shown in Figs. 3-4) consisted of a chassis, engine, cabin, and implement. The engine was set to provide constant forward motion at a speed of $0.2 \mathrm{~m} / \mathrm{s}$. To measure the ground reaction force applied to each obstacle-surmounting tire, force-sensing resistor devices and a motion sensor were installed. Moreover, as the value of reaction force applied on the left side of the tire is different than the force on the right side of the tire, we prepared two sensing devices for the force measurement of each tire. The sum of the two signals represents the value of the ground reaction force.

To provide different slope angles for the experiments, the main baseboard (No. 1 in Fig. 3) was designed to be rotatable around the axis of the forward direction. As reported by Hamdeh, a tractor becomes unstable when towing a $3,750 \mathrm{~kg}$ trailer uphill on a slope of $28^{\circ}$ (Hamdeh, et al., 2004). A similar result was obtained by Abubakar, who showed that when tractor stability is the main concern, a slope of $15^{\circ}$ must be classified as steep and a slope of $30^{\circ}$ as extremely steep (Abubakar, et al., 2010). During our experiments, these results were confirmed, in that rollover occurred when the scale-model tractor operated on road class $\mathrm{H}$ at a slope angle of $25^{\circ}$ or $30^{\circ}$. Therefore, tests with a slope angle above $30^{\circ}$ were abandoned, as they were beyond the limits of an operable slope. Thus, the final tested slope angles ranged from $0^{\circ}$ to $30^{\circ}$ in $5^{\circ}$ increments, which provided seven tests for each road class. Based on the updated experimental system, including all eight classes of scale-model road surface, 56 traveling experiments were performed in this study.

\section{Evaluation of Tractor Stability}

Tractor stability evaluation is widely used in the field of rollover warning development. The warning triggered by evaluation afford the operators additional reaction time, during which they can take corrective action to save their lives. Likewise, engineers benefit from it because it provides an easy-to-follow approach for predict the state of tractor and further improving tractor stability.
The most popular stability evaluation, load transfer ratio (LTR), was put forward by Thoms and Woodrooffe in 1990. For a single axis, the definition of the lateral load transfer rate can be understood as the ratio of the absolute value of difference between vertical force of the left and right tires and their sum, defined as

$$
L T R=\frac{\left|F_{u p}-F_{\text {down }}\right|}{F_{u p}+F_{\text {down }}}
$$

Considering this formula, LTR is an index that varies in $[0,1]$. The tractor will be more stable if LTR is near 0 ; conversely, the tractor stability decreases as the value approaches 1 .

However, since the tractor's uphill tires are usually more susceptible to disturbance than the downhill tires, as the initiation of rollover begins from the separation of uphill tires and the ground when the tractor operates on a slope. Thus, we need an indicator that focuses on the state of the uphill tires. Therefore, we introduced a new parameters, $F_{\text {steady }}$, in our experiment, which is used to define the stability evaluation load loss rate (LLR) whose physical meaning is expressed by

$$
L L R_{f / r}=\left(1-\frac{F_{f / r-u p}}{F_{f / r-u p-\text { steady }}}\right) 100 \%
$$

According to this formula, for a tractor running on the side slope of a full-scale random road, the $L L R$ varies from $0 \%$ to $100 \%$. The tractor becomes more unstable as the $L L R$ approaches $100 \%$, until the uphill tires separate from the ground when $L L R$ becomes $100 \%$. Thus, the $L L R$ is understood to be $100 \%$ when one or more tires separate from the ground.

Furthermore, by focusing on the tractor's lateral stability, we translate the $L L R$ values for the front and rear axles into overall stability evaluation using a weighted summation method according to the conclusion that the load on the steerable axle accounts for $20 \%$ of the total instantaneous weight of a tractor with attached implements below 3,200 kg (Habarta, 1971). Thus, the translated expression is

$$
L L R_{t}=0.2 L L R_{f}+0.8 L L R_{r}
$$

\section{RESULTS AND DISCUSSION}

Figure 4 presents the coupled effect of slope angle and road roughness on tractor stability characteristics revealed by $L L R_{t}$. As a larger value of $L L R_{t}$ indicates a more unstable stage of the tractor, the general trend is an evident increase in $L L R_{t}$ as the slope angle and road roughness increase, which means that the tractor stability decreases during that progression. A high degree of road roughness and large slope angle are critical factors that reduce the stability of the tractor, but neither of them plays a decisive role; that is, the decrease of tractor 


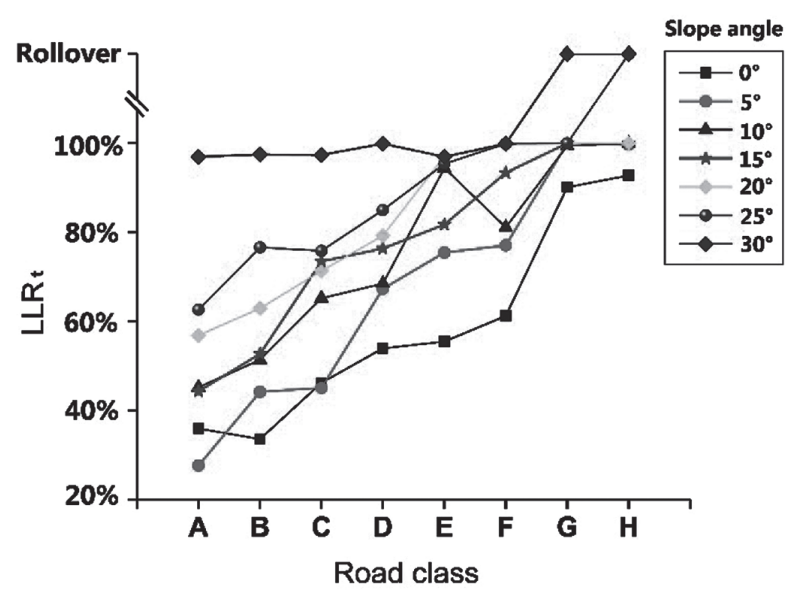

Fig. 4. Coupled effect of slope angle and road roughness on tractor stability characteristics revealed by $L L R_{t}$

stability is the result of their coupled effect. The results provide a reference for operators to avoid rollover and for researchers to make further investigations. Moreover, there is a critical need to conduct further research to obtain a better understanding of the coupled effect.
Figure 5 involving a contour map and a scatter plot presents the changing trend of $L L R_{f}$ with increasing slope angle and road class for the uphill front wheel. As shown in Fig. 5(a), the results for road classes $\mathrm{G}$ and $\mathrm{H}$ reveal that, when driving on extremely high degrees of road roughness, the tractor remains in an unstable state regardless of the slope angle. When the tractor traveled on a fixed road, the general trend is for $L L R_{f}$ to increase as the slope angle increase, which means that the front axle stability decreases. Also, Fig. 5 (b) reveals a similar trend for $L L R_{f}$ as the road roughness increases while the slope angle remains unchanged. Specifically, $L L R_{f}$ sharply increases between road classes $\mathrm{E}$ and $\mathrm{G}$, which means that road classes $\mathrm{E}$ and $\mathrm{F}$ maybe a boundary between tractor stability and instability. Besides, we point out the phenomenon that rollover does not occur at the extreme points (class $\mathrm{A}$ at $30^{\circ}$ and class $\mathrm{H}$ at $0^{\circ}$ ), but does occur when both factors reach their upper limit (class $\mathrm{H}$ at $30^{\circ}$ ). This fact reveals that only the combined effects of the two factors can lead to a rollover. Fig. 5(b) also reveals that for the front axle, the degree of road class makes greater influence on its stability than slope angle.

Results of tractor rear axle stability evaluated with $L L R_{r}$ indexes are shown in Fig. 6. The coupled effect (a)

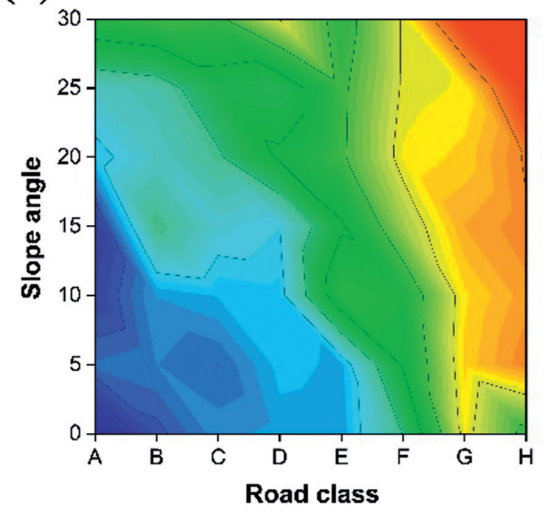

LLR

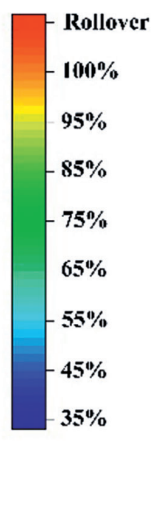

(b)

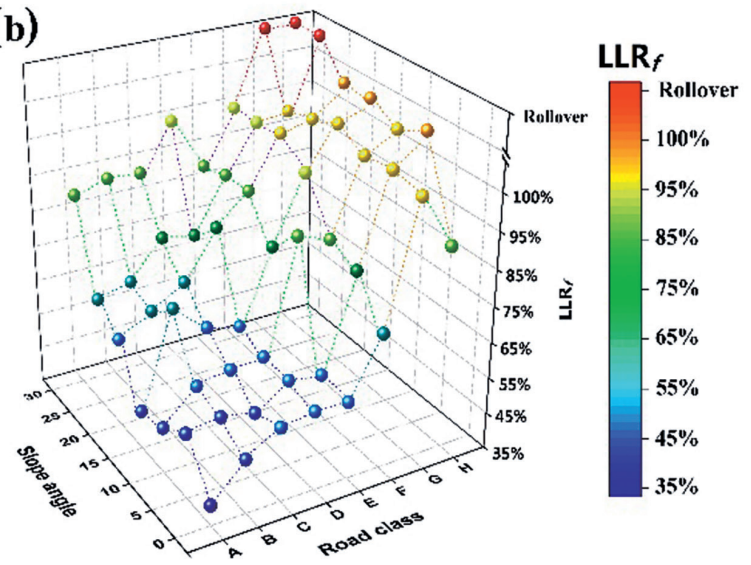

Fig. 5. Experimental results for $L L R_{f}$ of uphill front wheel: (a) contour map; (b) scatter plot.

(a)

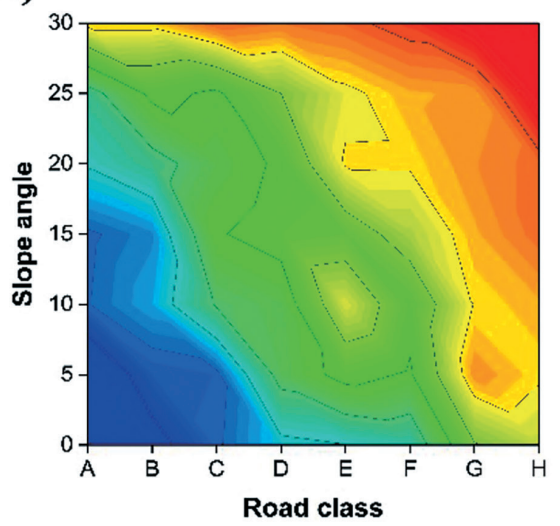

LLR,

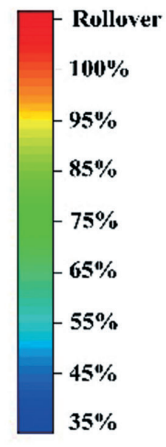

(b)

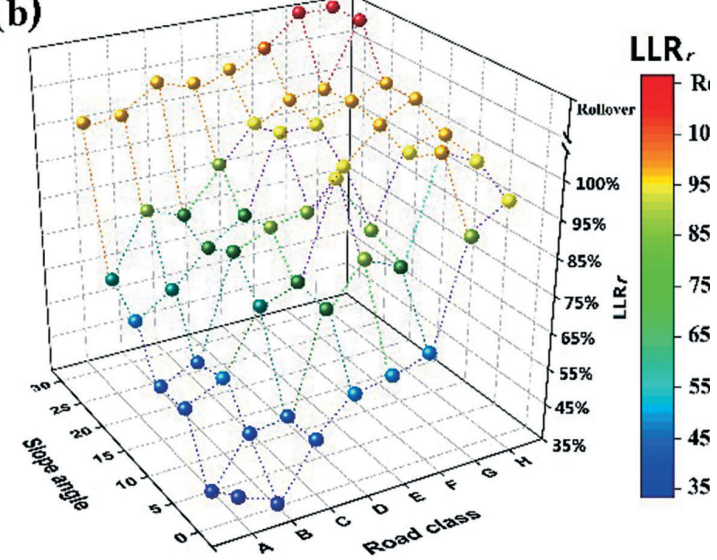

Fig. 6. Experimental results for $L L R_{r}$ of uphill rear wheel: (a) contour map; (b) scatter plot. 
has a trend similar to that for front axle stability, but more phenomena need further investigation. First, we note that all the $L L R_{r}$ values in Fig. 6 are obviously much larger than in Fig. 5, revealing that the increase of slope angle and road roughness affect the rear axle stability much more significantly than the front. The point of class $\mathrm{E}$ at $10^{\circ}$ in Fig, 6(a) represents a deviation from the overall trend; we confirmed it as an outlier by repeated testing. Moreover, as shown in Fig. 6(b), the rear axle of the tractor lost its balance when the tractor operated on slopes of $30^{\circ}$ regardless of road roughness. The sharp increase of $L L R_{r}$ between $25^{\circ}$ and $30^{\circ}$ shown in Fig. 6(b) tells us that $30^{\circ}$ may be the boundary between tractor stability and instability. Besides, different from the front axle, the slope angle has a greater influence on its stability than the degree of road class for the rear axle which is revealed by Fig. 6(b).

\section{CONCLUSIONS}

Previous studies have explored the effect of slope angle and terrain roughness on tractor stability by establishing models and related experiments, and the consensus is that a large slope angle and high level of terrain roughness will contribute to the reduction of tractor stability. However, no related experiments revealed the coupled effect of slope angle and terrain roughness on tractor stability characteristics.

This study updated a previously developed experimental system by adding road roughness classes to include all eight classes defined by ISO 8608 (2016), making it possible to obtain the reaction forces between uphill tires and the ground. Furthermore, we developed the indicator $L L R$ to predict the risk of tractor rollover. In the experiments, we observed seven slopes from $0^{\circ}$ to $30^{\circ}$ for all eight road roughness classes, for a total of 56 tests to thoroughly evaluate the effects of both factors on tractor stability.

The $L L R$ results revealed that the rear axle of the tractor is more greatly affected by the increase of slope angle and road roughness than the front axle, so the rear axles should receive more attention for operating a tractor on slopes. Furthermore, rollovers were generally caused by extreme conditions brought about by the combined effects of the two factors. In other words, rollover accidents can be avoided by reducing the magnitude of either factor. Also, for the rear axle, a slope angle of $30^{\circ}$ may be the upper limit for safe operation. We reconfirmed a conclusion from our previous study that extremely high degrees of road roughness will decrease tractor stability. Besides, the result shows that for the front axle, the degree of road class makes greater influence on its stability than slope angle while there is an opposite conclusion for the rear axle.

The results of this updated scale-model-based experimental system qualitatively and quantitatively described the coupled effect of slope angle and terrain roughness on tractor stability. The methods and findings of this work could provide engineers a reference for designing tractors with higher stability and provide opera- tors criteria for avoiding rollover when operating on a road with a rough surface and extremely steep slope.

\section{AUTHOR CONTRIBUTIONS}

J. Qin performed the experiments, analyzed the data and wrote this paper. Z. Zhu designed the study and participated in performing the experiments. M. Mitsuoka participated in the design of the study and performed the statistical analysis. E. Inoue, T. Okayasu, Y. Hirai, Z. $\mathrm{Li}$ and Z. Song designed the study, supervised the work and provided facilities and resources. All authors assisted in editing of the manuscript and approved the final version.

\section{ACKNOWLEDGEMENTS}

The authors would like to acknowledge the financial support from the National Key Research and Development Program of China (No. 2016YFD0700504).

\section{REFERENCES}

Ahmadi, I. 2011 Dynamics of tractor lateral overturn on slopes under the influence of position disturbances (model development). Journal of Terramechanics, 48(5): 339-346

Abubakar, M. S., Ahmad, D. and Akande, D. 2010 A review of farm tractor overturning accidents and safety. Pertanika Journal of Science and Technology, 18(2): 377-385

Abu-Hamdeh, N. H. and Al-Jalil, H. F. 2004 Computer simulation of stability and control of tractor-trailed implement combinations under different operating conditions. Simulação computacional da estabilidade e controle de combinações trator-carreta sob diferentes condições de operação, 63(1): 149-162

Ballesteros, T., Arana, I., Ezcurdia, A. P. and Alfaro, J. R. 2013 E2D-ROPS: Development and tests of an automatically deployable, in height and width, front-mounted ROPS for narrowtrack tractors. Biosystems Engineering, 116(1): 1-14

Ballesteros, T., Arana, I., Ezcurdia, A. P. and Alfaro, J. R. 2015 Development and validation of automatically deployable ROPS based on airbag inflator technology. Biosystems Engineering, 130: $92-105$

Bietresato, M., Carabin, G., Vidoni, R., Mazzetto, F. and Gasparetto, A. 2015 A Parametric Approach for Evaluating the Stability of Agricultural Tractors Using Implements during Side-Slope Activities. Contemporary Engineering Sciences, 8: 1289-1309

Gibson, H. G., Elliott, K. C. and Persson, S. P. E. 1971 Side slope stabiity of articulated frame logging tractors. Journal of Terramechanics, 2(8): 65-79

Habarta, F. 1971 Determination in relation to safety of operation of the minimal load on the front steering axle of a tractor with implements attached. Journal of Agricultural Engineering Research, 16(2): 126-140

Li, Z., Mitsuoka, M., Inoue, E., Okayasu, T. and Hirai, Y. 2014 Lateral Slope Effect on Tipping Behavior of a Tractor Encountering an Obstacle (Model Development). J. Fac. Agr., Kyushu Univ, $\mathbf{5 9}(2)$ : 345-349

Li, Z., Mitsuoka, M., Inoue, E., Okayasu, T. and Hirai, Y. 2015 Development of stability indicators for dynamic Phase I overturn of conventional farm tractors with front axle pivot. Biosystems Engineering, 134: 55-67

Matthews, J. 1966 Ride comfort for tractor operators. Journal of Agricultural Engineering Research, 11(1): 44-57

International Organization for Standardization. 2016 ISO 8608: Mechanical vibration - Road surface profiles - Reporting of measured data. Genève, Switzerland: International Organization 
for Standardization.

Ohmiya, K. 1990 Studies on roughness of meadow. Memoirs of the Faculty of Agriculture-Hokkaido University (Japan), 17

Ayers, P. and Khorsandi, F. 2017 Reducing Tractor Rollover Fatalities. Resource Engineering \& Technology for Sustainable World, 24(6): 6-7

Report on fatal farming accidents that happened in 2013 (in Japanese, 15 April 2015). Ministry of Agriculture, Forestry and Fisheries of Japan. Available from http://www.maff.go.jp/j/ press/seisan/sien/pdf/150415-01.pdf.

Torisu, R., Matsuo, M. and Morishima, S. 1979 Characteristics of the Agricultural Surface Undulations as Origins of Farm Tractor Vibrations. Science Bulletin of the Faculty of Agriculture, 34: $7-17$

Taghavifar, H., Motlagh, A. M., Mardani, A., Hassanpour, A., Hosseinloo, A. H. and Wei, C. 2016 The induced shock and impact force as affected by the obstacle geometric factors during tire-obstacle collision dynamics. Measurement, 84: 47-55

Takeda, J., Shimada, M., Kikuchi, Y., Nakano, M., Okada, S. and Hiroma, T., et al. 2010 Dynamic behaviors of farm tractor passing over an obstacle. (Part I) - Improvement of tractor dynamic model and measurement of tire stiffness. Journal of the
Japanese Society of Agricultural Machinery, 72: 457-463

Takeda, J., Shimada, M., Kikuchi, Y., Nakano, M., Okada, S. and Hiroma, T., et al. 2010 Dynamic behaviors of farm tractor passing over an obstacle. (Part 2) - Analysis on validation for improved dynamic model. Journal of the Japanese Society of Agricultural Machinery, 72(5): 464-470

Vidoni, R., Bietresato, M., Gasparetto, A. and Mazzetto, F. 2015 Corrigendum to "evaluation and stability comparison of different vehicle configurations for robotic agricultural operations on side-slopes". Biosystems Engineering, 129(5): 197-211

Yang, J. H., Sakai, H. and Murayama, S. 1991 Side over-turning of articulated-frame skidder running along a contour line. Journal of the Japanese Forestry Society, 73(1): 1-10

Yisa, M. G., Terao, H. and Kubota, M. 1995 Dynamics of tractorimplement combinations on slopes (part II) -computer simulation of directional dynamics. Journal of the Faculty of Agriculture Hokkaido University, 66(2): 263-275

Zhu, Y. H., Hou, J. X. and Zhou, Y. M. 1986 A Model Test Method for Studying Dynamic Tilting Characteristics of Tractors Development of Tilting Test Model for Remote Tractor. Transactions of the Chinese Society for Agricultural Machinery, 3: 17-23 